\title{
Phytopharmacological overview of Psidium guajava Linn.
}

\author{
Vijaya Anand', Manikandan², Vijaya Kumar², Sampath Kumar, Pushpa', Agaath Hedina' \\ 'Department of Human Genetics and Molecular Biology, Bharathiar University, Coimbatore-641 046, Tamil Nadu, INDIA. \\ ${ }^{2}$ Department of Biochemistry, M.I.E.T. Arts and Science College, Tiruchirappalli-620 007, Tamil Nadu, INDIA. \\ ${ }^{3}$ Department of Chemistry and Biosciences, SASTRA University, Kumbakonam-612 001, Tamil Nadu, INDIA. \\ ${ }^{4}$ Department of Microbiology, Cauvery College for Women, Tiruchirappalli-620 018, Tamil Nadu, INDIA.
}

\begin{abstract}
Psidium guajava Linn. possesses useful medicinal benefits. It has been recognized as the medicinally essential phytoconstituents, such as phenolic, flavonoid and carotenoid. Numerous pharmacological investigation have confirmed that the ability of this plant is to exhibit antimicrobial, antidiabetic, cardioprotective, neuroprotective, hepatoprotective, antioxidant and anticancer activities and it supports the traditional uses. This is a comprehensive of the phytoconstituents and pharmacological benefits.
\end{abstract}

Key words: Psidium guajava, Antimicrobial, Antidiabetic, Antioxidant, Hepatoprotective, Anticancer.
Corresponding author:

Dr. A. Vijaya Anand,

Associate Professor and Head, Department of Human Genetics and

Molecular Biology, Bharathiar University, Coimbatore-641 046,

Tamil Nadu, INDIA.

Mobile: +919842525830

E-mail: avamiet@yahoo.com

DOI: 10.5530/pj.2016.4.3

\section{INTRODUCTION}

Psidium guajava Linn. is commonly called guave, goyave in French; guave, guavenbaum, in German; banjiro in Japanese; goiaba, in Portugal; arac, guaiaba in Brazil; and guava in English. ${ }^{1}$ P. guajava used as an important food as well as a medicinal plant in tropical and subtropical countries, therefore its nickname as the poor man's apple. The scientific evidences of the medicinal uses of P. guajava began in 1940's and reports, maintain a tradition of repeating the data each decade.

Many people habitually take $P$. guajava leaf decoction for its antispasmodic and antimicrobial properties for the treatment of dysentery and diarrhea. ${ }^{2}$ Therefore, the efficacy and safety of $P$. guajava leaves have empirically been confirmed. ${ }^{3}$ P. guajava leaf contains plenty of phenolic compounds which inhibit the peroxidation reaction in the body, and so it can be expected to prevent various chronic diseases such as diabetes, cardiovascular disease and cancer. ${ }^{2}$ Furthermore, decreasing of free radicals in the body, means that the polyphenols in the leaf of $P$. guajava can prevent atherosclerosis, cataract and also inhibits biological aging of the body and skin. ${ }^{4}$

P. guajava leaves contains triterpenes, cineol and tannins. Additionally, three lavonoids (avicularin, guaijaverin, and quercetin) have been isolated from the leaves. ${ }^{5}$ In mature leaves, the greatest concentrations of flavonoids are found in: Quercetin $>$ Myricetin $>$ Kaempferol $>$ Luteolin. ${ }^{6}$ Most of the medicinal activities of P. guajava are credited to the flavonoids and these phytoconstituents are well-known for their multi-directional medicinal activities. This review focuses on the phytochemical and pharmacological benefits of P. guajava from the internet data base PubMed and the most relevant articles are considered for review.

\section{PHYTOCHEMISTRY OF LEAVES}

Matsuo et al. ${ }^{7}$ isolated (+)-gallocatechin from the $\mathrm{MeOH}$-extract of P. guajava leaves. P. guajava leaves contains various components such as, menthol, $\alpha$-pinene, $\beta$-bisabolene, $\beta$-pinene, $\beta$-copanene, limonene, terpenyl acetate, isopropyl alcohol, caryophyllene, longicyclene, cineol, caryophyllene oxide, humulene, farnesene, selinene, curcumene and cardinene. ${ }^{8}$

The sixteen carotenoids identified are phytofluene, (all-E)-, (9Z)-, (13Z)-, and (15Z)-beta-carotene, (all-E)-gamma-carotene, (all-E)-,
(9Z)-, (13Z)-, and (15Z)-lycopene, (all-E,3R)-beta-cryptoxanthin, (allE, 3R)-rubixanthin, (all-E,3S,5R,8S)-cryptoflavin, (all-E,3R,3'R, 6'R)lutein, (all-E,3S,5R,6R,3'S,5'R,8'R)-, and (all-E,3S,5R,6R,3'S, 5'R,8'S)neochrome. ${ }^{9}$ Guavanoic acid, guavacoumaric acid, $2 \alpha$-hydroxyursolic acid, isoneriucoumaric acid, jacoumaric acid, asiatic acid, ilelatifol $\mathrm{d}$ and $\beta$-sitosterol-3-O- $\beta$-D-glucopyranoside have also been isolated from the leaves of $P$. guajava. ${ }^{10}$

Two triterpenoids, guavanoic acid (20 $\beta$-acetoxy- $\alpha$, $3 \beta$-dihydroxyurs12-en-28-oic acid), and guavacoumaric acid ( $2 \alpha, 3 \beta$ dihydroxy-24- $p$ - $z$ coumaroyloxyurs-12-en-28-oic acid), along with six known compounds asiatic acid, jacoumaric acid, $2 \alpha$-hydroxyursolic acid, isoneriucoumaric acid, $\beta$-sitosterol-3-O- $\beta$-D-glucopyranoside, and ilelatifol $\mathrm{d}$, have been isolated from the leaves of $P$. guajava. ${ }^{11}$ Two new triterpenoids, guajavolide ( $2 \mathrm{a}-, 3 \beta-6 \beta$-, 23-tetrahydroxyurs-12-en-28, 20 $\beta$-olide, and guavenoic acid ( 2 alpha, 3 beta, 6 beta,23-tetrahydroxyurs-12,20(30)-dien28-oic acid), are also isolated along with one known triterpene oleanolic acid from fresh leaves of P. guajava. ${ }^{10}$

Begum et al. ${ }^{12}$ isolated three pentacyclic triterpenoids including one new guajavanoic acid and two known obtusinin and goreishic acid I from the leaves of $P$. guajava. Five constituents, including one new pentacyclic triterpenoid guajanoic acid and four known compounds beta-sitosterol, uvaol, oleanolic acid, and ursolic acid have been isolated from the leaves of $P$. guajava. ${ }^{13}$ One new pentacyclic triterpenoid psidiumoic acid along with four known compounds beta-sitosterol, obtusol, oleanolic acid, and ursolic acid have been isolated from the leaves of $P$. guajava. ${ }^{14}$ Guajadial is a novel compound isolated caryophyllene-based meroterpenoid compound, from the leaves of P. guajava. ${ }^{15}$

Ghosh et $a^{16}$ isolated betulinic acid and lupeol from the leaf extract of P. guajava. Shu et al ${ }^{17}$ isolated ellagic acid-4-O-beta-D-glucopyranoside and quercetin-3-O-(6"-galloyl) beta-D-galactopyranoside from P. guaja$v a$ for the first time, and 1-O-(1,2-propanediol)-6-O-galloyl-beta-D-glucopyranoside is a new polyhydroxyl compound. Metwally et al ${ }^{18}$ isolated five flavonoidal compounds from $P$. guajava leaves (quercetin, quercetin3-O- $\alpha$-L-arabinofuranoside, quercetin-3-O- $\beta$-D-arabinopyranoside, quercetin-3-O- $\beta$-D-glucoside and quercetin-3-O- $\beta$-D-galactoside). $( \pm)$-Guajadial B, an unusual humulene-based meroterpenoid, is isolated as a racemate from the leaves of P. guajava. ${ }^{19}$ 
Ryu et $a l^{20}$ identified 60 compounds in a hexane fraction of P. guajava, including $\beta$-eudesmol, $\alpha$-copaene, phytol, $\alpha$-patchoulene, $\beta$-caryophyllene oxide, caryophylla-3(15),7(14)-dien-6-ol, (E)-methyl isoeugenol, a-terpineol, and octadecane. Shao et $a^{21}$ isolated and identified clovane- 2 beta, 9 alpha-diol, 2 beta-acetoxyclovan- 9 alpha-ol, 9 beta-diol, ent-T-muurolol, clov-2-ene-9 alpha-ol, (+)-globulol, (+)-caryolane-1, isophytol, gossypetin, tamarixetin, kaempferol, guajaverin, quercetin, avicularin, chrysin 6-C-glucoside, guavinoside A, guavinoside B 3'-Omethyl-3, 4-methylenedioxyellagic acid 4'-O-beta-D-glucopyranoside and p-hydroxy-benzoic acid.

\section{ANTIMICROBIAL ACTIVITY}

$P$. guajava leaf extract ( 2 and $5 \mathrm{~g} / \mathrm{kg}$ ) reduced the occurrence of cough induced by capsaicin aerosol by 35 and $54 \%$, respectively, within $10 \mathrm{~min}$ after injection of the extract. The growth of Staphylococcus aureus and beta-streptococcus group A, is inhibited by aqueous, methanol and chloroform extract of dry $P$. guajava leaves. Therefore $P$. guajava leaf extract may be recommended for cough..$^{22}$ Vieira et a ${ }^{23}$ have reported the antibacterial effect of $P$. guajava leaves extracts and found that they inhibited the growth of the $S$. aureus.

The methanolic plant leaf extracts of P. guajava and barks of this plant have antimicrobial activity. The organism inhibited is Salmonella species, Bacillus species, and the concentrations vary according to the organisms. ${ }^{24}$ The microbicidial activity of $P$. guajava is attributable to guajaverine and to psydiolic acid. The active flavonoid compound guaijaverin extracted from the leaves of the same plant is reported to have high potential antiplaque activity. ${ }^{25}$

The in vitro antibacterial activity of $P$. guajava leaf extracts of $S$. aureus is possibly due to protein degrading activity of the extracts. ${ }^{26} P$. guajava leaves flavonoids are also shown to have bacteriostatic effects on fish pathogenic bacteria. ${ }^{27}$ P. guajava and Azadirachta indica extracts showed higher antimicrobial activity food borne pathogens of Gram-positive bacteria than Gram-negative bacteria (except for Vibrio parahaemolyticus, Pseudomonas aeroginosa, and Acromonas hydrophila. ${ }^{28}$

The $\gamma$-terpinene and $\gamma$-pinene obtained by hydro distillation showed antimicrobial activity against Propionibacterium acnes. ${ }^{29}$ Minimum inhibitory concentration is found in the methanolic $(625 \mathrm{ug} / \mathrm{ml})$ and aqueous $(7.5 \mathrm{mg} / \mathrm{ml})$ leaf extracts of $P$. guajava and minimum bactericidal concentration recorded for methanolic $(1.25 \mathrm{mg} / \mathrm{ml})$ and aqueous extracts $(12.5 \mathrm{mg} / \mathrm{ml})$ against multidrug resistant clinical isolates of $S$. aureus strains. Human RBC based haemolytic assay showed absence of haemolysis and this confirms its safety. ${ }^{30}$

The essential oil from leaf extract of P. guajava exhibited the inhibitory activity towards $S$. aureus and Salmonella species. ${ }^{31}$ Pelegrini et al ${ }^{32}$ isolated the peptide Pg-AMP1 from the seeds of P. guajava. Pg-AMP1 showed growth reduction in Klebsiella sp. and Proteus sp. The recombinant Pg-AMP1 peptide showed inhibitory activity against Escherichia coli, K. pneumonia, P. aeruginosa, S. aureus, and S. epidermides bacteria. ${ }^{33}$ Metwally et $a l^{18}$ isolated five flavanoids from P. guajava leaves and found that good antimicrobial activity of the extracts, as well as the isolated compounds. Crude aqueous mixture and water soluble methanol extract from leaf and bark of $P$. guajava showed strong antibacterial activity against multidrug-resistant $V$. cholera. ${ }^{34}$ The decoction of $P$. guajava showed antibacterial activity against Shigella flexneri and $V$. cholerae. It reduced the production of cholera toxin and labile toxin as well as their binding to ganglioside monosialic acid. ${ }^{35}$ Mao et $a l^{36}$ purified and concentrated total saponin from $P$. guajava leaf. It interferes with the envelope subunit gp41 form the critical 6-HB structure, thus inhibit the entry of HIV into target cells.

Dhiman et $a^{37}$ found that methanolic extract of P. guajava leaf has bacteriostatic and fungistatic in action. P. guajava tea showed efficient control of epidemic and pandemic influenza viruses, including oseltamivir-resistant strains, and its broad target blockage makes it less likely to lead to the emergence of viral resistance. ${ }^{38}$

P. guajava might be valuable sources for the synthesis of new antibacterial agents against Helicobacter pylori. ${ }^{39}$ Methanolic and ethanolic extract of $P$. guajava leaf showed antimicrobial activities against $E$. coli and Salmonella enteritidis..$^{40}$ Acetone-water extract of $P$. guajava have catechin and it may be showed antimicrobial, anti-inflammatory and analgesic properties. ${ }^{41}$ From these results, $P$. guajava extracts may contribute the novel antibiotics from natural resources.

\section{ANTIDIARRHOEAL ACTIVITY}

Lutterodt ${ }^{42}$ isolated quercetin and quercetin-3-arabinoside, from P. guajava leaf. The leaf extract has a morphine-like inhibition of the release of acetylcholine in the coaxially stimulated ileum, with an initial increase, followed by a gradual decrease of muscular tone. Quercetin inhibited intestinal contraction induced by different concentrations of calcium. The ileum is being more sensitive to quercetin. These calcium-antagonist properties of quercetin explain the spasmolytic effect of this popular herbal remedy. ${ }^{43}$ Lozoya $e t ~ a l^{44}$ suggested that the aglycone quercetin in P. guajava leaf may be responsible for spasmolytic activity.

\section{ANTI-INFLAMMATORY ACTIVITY}

Ethyl acetate extract of $P$. guajava suppressed the interferon gama $(\mathrm{IFN}-\gamma) / \mathrm{TNF}-\alpha-\mathrm{co}-$ induced production of thymus and activation-regulated chemokine protein and mRNA in HaCaT cells. It also inhibited the TNF- $\alpha /$ IFN- $\gamma$-co-induced activation of STAT1 and NF- $\kappa B$ as well as increased the expression of mRNA and heme oxygenase-1 protein. This demonstrates that $P$. guajava inhibits expression of chemokine in keratinocytes by inducing heme oxygenase- 1 expression and it highlight the therapeutic uses of P. guajava in atopic dermatitis and inflammatory skin diseases. ${ }^{45}$

Ethanolic extract of P. guajava leaf significantly inhibited lipopolysaccharide induced production of nitric oxide and prostaglandin E2 in a concentration-dependent manner. P. guajava extract suppressed the expression and activity of inducible nitric oxide synthase and cyclooxygenase-2 through the downregulation of ERK1/2 activation in RAW264.7 macrophages. It also exhibited significant anti-inflammatory activity in 2 different animal models. ${ }^{46}$

Ethyl acetate of $P$. guajava reduced antigen, induced the release of $\beta$-hexosaminidase and histamine in IgE-sensitized RBL-2H3 cells. It also inhibited expression of IL- 4 and TNF- $\alpha$ mRNA and protein production. It suppressed antigen-induced COX-2 mRNA and protein expression in these cells, as well as antigen-induced activation of NFAT and reactive oxygen species (ROS). Moreover, it inhibited antigen-induced activa-

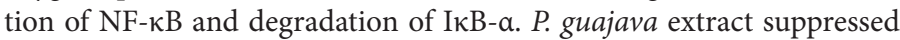
antigen-induced phosphorylation of Syk, LAT, Gab2, and PLC $\gamma 2$ but not Lyn, and inhibited antigen-induced phosphorylation of downstream signaling intermediates including MAP kinases and Akt. ${ }^{47}$

Matsuzaki et $a l^{48}$ isolated benzophenone and flavonol galloyl glycosides from $80 \% \mathrm{MeOH}$ extract of $P$. guajava together with five known quercetin glycosides. These compounds showed significant inhibitory activities against histamine release from rat peritoneal mast cells, and nitric oxide production from a murine macrophage-like cell line.

\section{ANTIOXIDANT ACTIVITY}

Ethanolic and aqueous leaf extract of $P$. guajava contain high total phenolic content $(575.3 \pm 5.5$ and $511.6 \pm 6.2 \mathrm{mg}$ of gallic acid equivalent/g, respectively). The higher the sample concentration used, the stronger is 
the free radical-scavenging effect. ${ }^{49}$ Akinola et $a l^{50}$ suggested that ethanolic leaf extract of P. guajava possesses the beneficial effect on gossypol-induced sperm toxicity, and hence it may enhance male fertility due to rich natural antioxidants in it. The total flavonoids are primarily identified in the aqueous and ethanolic leaf extracts of $P$. guajava which may possess the potential antioxidative activities. ${ }^{51}$ The ethanolic extracts of the leaves of $P$. guajava possess beneficial effects on sperm production and quality, and may thus improve the sperm parameters of infertile males with oligospermia and nonobstructive azoospermia. ${ }^{52}$

Shabana $e a^{53}$ isolated quercetin and two quercetin glycosides (avicularin and guaijaverin) from $P$. guajava and have urease inhibitory activity. Free radical scavenging activity of the P. guajava leaves harvested during May and August are high, and have higher amounts of acetic acid, 3-hydroxybutyric acid, glutamic acid, citric acid, malonic acid, trans-aconitic acid, ascorbic acid, maleic acid, cis-aconitic acid, protocatechuic acid, asparagine, xanthine, and epicatechin than the leaves harvested during October and December. Epicatechin and protocatechuic acid seems to have enhanced, free radical scavenging activity of the $P$. guajava leaves. ${ }^{54}$ Methanolic extract of $P$. guajava contains the highest amount of total phenolics (380.08 $\pm 4.40 \mathrm{mg} / \mathrm{L}$ gallic acid equivalents), $P$. guajava contains high amount of total flavonoids $(269.72 \pm 2.78 \mathrm{microg} / \mathrm{mL})$ among 10 Nigerian plants. Percentage 2,2-Diphenyl-1-picryl hydrazyl (DPPH) radical scavenging activity $(82.79 \pm 2.84 \%)$ and reductive potentials $(0.79 \pm 0.04)$ also higher P. guajava. ${ }^{55}$

Nantitanon and Okonogi ${ }^{56}$ isolated quercetin, morin, and quercetin3-O-glucopyranoside from leaf of P. guajava. Quercetin possess free radical scavenging activity approximately four times higher than morin and two times higher than quercetin-3-O-glucopyranoside. The reducing power of quercetin is eight times higher than morin and two times higher than quercetin-3-O-glucopyranoside. This confirmed that quercetin is the more active antioxidant from guava leaves.

Phorbol myristate acetate and the DPPH radical scavenging assay for the spray dried extracts of $P$. guajava presented significant antioxidant activity in a dose-dependent manner and showed no toxicity to the human neurtophils. ${ }^{57}$ The antioxidant activities of different solvents of $P$. guajava leaves (water, ethanol, methanol, and various concentrations of hydroethanol) have demonstrated that the antioxidant ability of $P$. guajava leaf extracts have a strong relationship with phenolic compound when compared to flavonoid content. ${ }^{58}$ Aqueous extract of $P$. guajava and its synthesized $\mathrm{TiO}_{2}$ nanoparticls are found to possess maximum antioxidant activity and antimicrobial activity when compared with ascorbic acid..$^{59}$

Recently, four new compounds, guavinoside C, D, E and F are isolated from the leaves of $P$. guajava and these compounds showed antioxidant activities in DPPH, 2,2'-azino-bis-3-ethyl benzthiazoline-6-sulphonic acid (ABTS) and ferric reducing antioxidant potential (FRAP) assays. ${ }^{60}$ Roasted P. guajava seeds showed higher DPPH radical scavenging and reducing power activities. ${ }^{61}$ These results indicate that $P$. guajava could be a suitable source of natural antioxidants.

The ethanolic extract of $P$. guajava has been found to show Antioxidant activity in all the tests done like DPPH assay, reducing power assay, nitric oxide scavenging assay, $\mathrm{H}_{2} \mathrm{O}_{2}$ radical scavenging assay and $\mathrm{SO}$ radical scavenging assay. ${ }^{62}$ The Antioxidant activity when evaluated in diabetic mice induced with streptozoin showed the decrease in level of glucose and lipid peroxides when treated with the ethanolic leaf extract of P. guajava. ${ }^{63}$

\section{ANTIDIABETIC ACTIVITY}

Treatment with guava juice $(1 \mathrm{~g} / \mathrm{kg}$ ) produced a noticeable hypoglycemic action in normal and alloxan-induced diabetic mice. ${ }^{64}$ Aqueous leaf extract of $P$. guajava (250 mg/kg), showed statistically significant hypo- glycemic activity ${ }^{65}$ Intraperitoneal injection of $P$. guajava leaf extract $(10 \mathrm{mg} / \mathrm{kg})$ exhibited a significant inhibitory effect on protein tyrosine phosphatase1B in 1- and 3-month-old $\operatorname{Lepr}(\mathrm{db}) / \operatorname{Lepr}(\mathrm{db})$ mice. The butanol-soluble fraction significantly decrease the number of lipid droplets. ${ }^{66}$ Ethanolic extract of stem bark of $P$. guajava exhibited significant hypoglycaemic activity in alloxan-induced hyperglycaemic rats. ${ }^{67}$

The aqueous leaf extract of $P$. guajava have the potential effect of inhibition of the alpha-glucosidase activity from the small intestinal mucosa of diabetic mouse. ${ }^{68}$ P. guajava bud extract has significant insulin-mimetic and potentiating activity. Noni leaf, noni, fruit commercial noni juice and mangrove bean have insulin-like activity with minimum effect on insulin action. Habitual intake of P. guajava and noni is proposed to offer better protection against type 2 diabetes mellitus. ${ }^{69}$

Shen et al ${ }^{70}$ investigated the effect of aqueous and ethanolic leaf extracts of P. guajava on hypoglycemia and glucose metabolism in streptozotocin induced type 2 diabetic rats. The acute and long-term feeding of the aqueous and ethanolic extract of $P$. guajava leaves have significantly decreased in the blood sugar level and increased the plasma insulin level. The activities of hepatic hexokinase and glucose-6-phosphate dehydrogenase is observed in diabetic rats fed with aqueous as well as ethanolic extracts and increased phosphofructokinase activity only in aqueous extract.

Unripe fruit peel aqueous extract guava has shown hypoglycaemic as well as antidiabetic effect in normal, mild and severely diabetic rats induced by streptozotocin..$^{71}$ Cheng et $a l^{72}$ identified and suggested that quercetin in the aqueous extract of $P$. guajava leaves promotes the uptake of glucose in rat clone 9 hepatocytes, which may contribute to the alleviation of hypoglycemia in diabetes.

Fructosamine and glycated hemoglobin are significantly reduced in ethyl acetate fraction of $P$. guajava leaf treated groups. It also improved the antioxidant potential by decreasing lipid peroxidation (LPO) and increasing in the activity of catalase (CAT), superoxide dismutase (SOD), glutathione peroxidase (GPx) and reduced glutathione (GR) ${ }^{73}$ Huang et al $l^{74}$ suggested that $P$. guajava fruit (125 and $250 \mathrm{mg} / \mathrm{kg}$ ) protected pancreatic tissues, against lipid peroxidation (LPO) and DNA strand breaks in streptozotocin induced diabetic rats. It also noticeably inhibited pancreatic expression of NF-kB protein and restored the activities of SOD, CAT and GPx.

Dipeptidyl-peptidase IV is an important enzyme which maintains blood glucose homeostasis. The ethanolic P. guajava and its components flavonol-glycoside inhibit dipeptidyl-peptidase IV in a dose-dependent manner. ${ }^{75}$ Ethanolic leaves extract of $P$. guajava showed a significant reduction in blood glucose and glycated hemoglobin levels as well as increase in plasma insulin levels in streptozotocin induced diabetic rats. It also restored the activities of carbohydrate metabolizing enzymes. ${ }^{76}$

Treatment with $P$. guajava leaf extracts promoted the expression of IRS1, AKT, PI3Kp85 and IRS-1, AMKP, and AKT308, phosphorylation, accompanied by increasing the ratios of the membrane to the total expression of glucose transporter 4 and adiponectin receptor 1 transcription in the skeletal muscles. ${ }^{77}$ These supports the modulating effect of $P$. guajava leaf extracts in insulin-related signaling.

The poly formulation of Anacardium occidentale, Eucalyptus globulus, $P$. guajava, and Xylopia aethiopica extracts yielded significant result as well as reduces some other complications associated with diabetes in alloxaninduced diabetic models. ${ }^{78}$ Recently, aqueous extract of $P$. guajava leaves (250 and $500 \mathrm{mg} / \mathrm{kg} / \mathrm{d}$ ) re-set the raised circulating levels of leptin, insulin, and hepatic glucose transporter expression to promote insulin resistance, dyslipidemia, and hypertension in high fructose intake male rats. ${ }^{79}$

\section{HEPATOPROTECTIVE ACTIVITY}

Aqueous leaf extracts of $P$. guajava at $250 \mathrm{mg} / \mathrm{kg}$ and $500 \mathrm{mg} / \mathrm{kg}$, significantly reduced the levels of aspartate transaminase (AST), alanine 
transaminase (ALT), alkaline phosphatase (ALP) and bilirubin. The higher dose of P. guajava extract guarded the increase in liver weight, whereas the lower dose of $P$. guajava extract is ineffective except in the paracetamol induced liver damage. In the chronic liver injury induced by $\mathrm{CCl}_{4}$, the higher dose of $P$. guajava leaf extract is found to be more effective than the lower dose..$^{80}$

In the acute liver damage induced by different hepatotoxins, methanolic, ethyl acetate and aqueous leaf extract of $P$. guajava $(200 \mathrm{mg} / \mathrm{kg}$, p.o.) significantly reduced the elevated serum levels of AST, ALT, ALP and bilirubin in $\mathrm{CCl}_{4}$ and paracetamol induced hepatotoxicity. Methanolic extract of leaves of $P$. guajava possesses better hepatoprotective activity compared to other extracts. Histological examinations of liver tissues also support the hepatoprotection. ${ }^{81}$

Pretreatment with aqueous extract of $P$ guajava leaf possesses, hepatoprotective property at lower dose $(150 \mathrm{mg} / \mathrm{kg})$ against erythromycin-induced liver damage and a hepatotoxic property at higher dose (300 and $450 \mathrm{mg} / \mathrm{kg}$ ) and recommended further studies with prolonged duration. Rai et $a^{82}$ evaluated the hypolipidaemic and hepatoprotective effects of unripe P. guajava fruit peel aqueous extract in streptozotocin induced severely diabetic rats. The extract has significant hepatoprotective and hypolipidaemic activity in addition to its antidiabetic activity.

\section{CARDIOPROTECTIVE AND HYPOTENSIVE ACTIVITY}

Aqueous-alcohol extract of P. guajava dry leaves depress the atrial contractility of guinea pig, in a dose-dependent fashion. The compound is concentrated using glacial acetic acid after removing the less polar fractions (acetone, chloroform, hexane, ethanol and methanol). The acetic acid fraction $(10-800 \mathrm{mg} / \mathrm{l})$ of $P$. guajava reduced myocardial force, increased the atrial relaxation time measured, abolished the positive staircase effect in a dose-dependent fashion suggesting a decrease of the cellular inward calcium current and its inotropic effect is abolished by cholinergic receptor blockade, indicating a cholinergic involvement in the mechanism of action of the extract. These data support that the extract of P. guajava leaves depress myocardial inotropism. ${ }^{83}$

Acute intravenous administrations of the aqueous extract of $P . g u a$ java leaf (50-800 mg/kg) produced a concentration-dependent, significant reduction in systemic arterial blood pressures and heart rates of hypertensive rats. The numerous phytoconstituents such as, polyphenolic compounds, flavonoids, pentacyclic triterpenoids, quercetin, guiajaverin, tannins, and other chemical compounds present in the plant are considered for the observed hypotensive effects of the plant leaf extract. ${ }^{84}$ Belemtougri et al ${ }^{85}$ evaluated P. guajava and Diospyros mespiliformis (crude decoction, aqueous and ethanolic extracts) for their antagonistic activities on caffeine induced release of calcium from the sarcoplasmic reticulum of skeletal muscle in rats. These different extracts have shown a decrease of caffeine induced calcium release in a dose-dependent manner. P. guajava leaf extracts are more active than D. mespiliformis and crude decoctions have shown better inhibitory activity.

Aqueous leaf extract of P. guajava produced dose-dependent (0.25-2 mg/ $\mathrm{ml}$ contracted aorta rings. The effect is then assessed in the presence of phentolamine and nifedipine. The sensitivity of the aortic rings to collective doses of $P$ guajava is significantly improved in the presence of phentolamine. These data suggest that the effect of $P$. guajava is either by activation of alpha-adrenoceptor or acting via a calcium ion channel. ${ }^{86}$

Quercetin and gallic acid is one of the major antioxidative bioactive compounds of $P$. guajava and Limonium wrightii, respectively. ${ }^{87}$ The extracts $P$. guajava and $L$. wrightii significantly attenuated ischemic contracture during ischemia and also enhanced myocardial dysfunction after reperfusion. Increases in malondialdehyde (MDA) and decreases in high-energy phosphates in the reperfused hearts are significantly lessened with the both plant extracts. Quercetin and gallic acid also exerted the same beneficial effects. These results indicate that $P$. guajava and L. wrightii have cardioprotective effects against myocardial ischemia-reperfusion injury in isolated rat hearts, primarily through their radical-scavenging actions.

Recently, the administration of the leaves extracts of $P$. guajava significantly reduced the blood glucose, fructosamine and glycated hemoglobin levels. Cardiac isoform of liver alpha 2 macroglobulin which is the major protein correlated with earlier stages of cardiac hypertrophy. This protein level is decreased significantly in extract treated groups and these findings support the benefits of extract for preventing cardiovascular complications associated with diabetes. ${ }^{88}$

\section{ANTICANCER ACTIVITY}

Research based on anticancer drug from natural compounds enabled the discovery of several drugs presently used in cancer therapy. P. guajava extracts modified the balance of Th1/Th2 to a dominant status of Th1 by directly reducing regulatory activity $\mathrm{T}$ cell. In pretreated mice exhibited retarded growth of s.c. inoculated B16 melanoma cells. ${ }^{89}$ $P$. guajava leaf oil showed the highest anti-proliferative activity with (4.37 times more potent than vincristine) than other 16 Thai medicinal platnsin P388 cell line. ${ }^{90}$

The aqueous extract of $P$. guajava inhibited the cancer cell DU-145 in a dose- and time-dependent manner. TUNEL assay and flow cytometric analysis confirmed the cell cycle arrests at G0/G1 phase. Additionally, suppression of the matrix metalloproteinases-2 (MMP-2) and matrix metalloproteinases-9 (MMP-9), and the upregulation of active caspase-3 in DU-145 are also effected in a dose-dependent manner, implicating a potent anti-metastasis power of $P$. guajava. ${ }^{91}$

P. guajava have huge amounts of soluble polyphenolics including gallic acid, catechin, epicatechin, quercetin, and rutin and to exhibit potent anticancer activity. ${ }^{92}$ Treatment with $P$. guajava arrests the cell cycle at G0/G1 phase with huge amount of apoptotic LNCaP cells. It also significantly diminished both the prostate specific antigen serum levels and tumor size in a xenograft mouse tumor model and is a promising antiandrogen-sensitive prostate cancer agent. ${ }^{93}$

Park et $a l^{94}$ isolated a sesquiterpene ( $\beta$-caryophyllene oxide) from the essential oils of $P$. guajava, Origanum vulgare, Cinnamomum sp, Eugenia caryophyllata and Piper nigrum. $\beta$-caryophyllene oxide inhibited the constitutive activation of $\mathrm{PI} 3 \mathrm{~K} / \mathrm{AKT} /$ mammalian target of rapamycin/ ribosomal p70 S6 signaling pathways; and also caused the activation of ERK, JNK, and p38 mitogen-activated protein kinase in tumor cells. It also down-regulated the expression of various downstream gene products that mediate cell proliferation, survival, metastasis, angiogenesis, and increased the expression of p53 and p21.

Aqueous soluble polyphenolic fraction of $P$. guajava leaves effectively inhibited the expressions of VEGF, IL- 6 and IL-8 cytokines, as well as MMP-2 and MMP-9. Simultaneously, it activated tissue inhibitor of metalloproteinases (TIMP-2) and suppressed the cell migration and the angiogenesis. P. guajava potentially possesses a strong anti-DU145 effect. ${ }^{95}$ Hexane fraction of P. guajava is the most powerful inducer of cytotoxic and apoptotic effects in PC-3 cells. It suppresses the AKT/mammalian target of rapamycin/ribosomal p70 S6 kinase and mitogen-activated protein kinase signaling pathways and this correlated with down-regulation of various proteins that mediate cell proliferation, cell survival, metastasis, as well as angiogenesis. ${ }^{20}$ The P. guajava extract exerted anticancer activity on haematological and solid neoplasias. P. guajava and its pulp ex- 
tract are found to induce the apoptosis, which accompanied by caspase activation and p16, p21, Fas ligand, Bcl-2-associated agonist of cell death as well as TNF receptor super-family, member $10 \mathrm{~b}$, over expression..$^{96}$

The ethanolic leaf extract of P. guajava showed inhibition (61.3\%) against the proliferation of colon cancer cell line SW $480 .{ }^{21}$ The $P$. guajava extracts contains the meroterpenes guajadial, psidial A and psiguadial A and $\mathrm{B}$. Both in vitro (nine human cancerlines) and in vivo (Solid Ehrlich murine breast adenocarcinoma model) showed to have highly effective anticancer property. The ability of the meroterpene-enriched fraction to reduce tumor growth and stimulate uterus proliferation, suggest that these compounds may act as Selective Estrogen Receptors Modulators. ${ }^{97}$ Kim et al ${ }^{98}$ also isolated $\beta$-caryophyllene oxide from the essential oils of $P$. guajava and $O$. vulgare. $\beta$-caryophyllene oxide suppressed constitutive STAT3 activation in multiple myeloma, prostate cancer and breast cancer cell lines. The suppression is mediated via the inhibition of activation of upstream kinases c-Src and JAK1/2. The inhibition of STAT3 activation subsequently inhibited the proliferation of cell, stimulated apoptosis and abrogated the invasive potential of tumor cells.

Overall, all these findings suggest that $P$. guajava leaves can interfere with various signaling pathways linked with tumorigenesis and provide a source of possible therapeutic compounds for cancer prevention and treatment.

\section{NEPHROPROTECTIVE ACTIVITY}

The aqueous extract of $P$. guajava fruits have more quercetin, myricetin, and caffeic acid and ethanolic extract have more ferulic acids, cinnamic acids, and coumaric acid. ${ }^{99}$ Aqueous and ethanloic extract intake at $2 \%$, significantly reduced glucose, blood urea nitrogen levels, and increased insulin level in plasma of diabetic mice. Both extracts, dose-dependently reserved glutathione content, retained activity of CAT and GPx, and decreased ROS, IL-6, TNF- $\alpha$ and interleukin-1 $\beta$ (IL-1 $\beta$ ) levels in the kidney. It also significantly declined renal $\mathrm{N}(\varepsilon)$-(carboxymethyl)lysine, pentosidine and fructose levels, and suppressed renal activity of aldose reductase. These findings support that guava fruit could protect the kidney against diabetic progression. ${ }^{99}$

Triterpenoids isolated from P. guajava leaves. ${ }^{100}$ The level of fasting blood glucose is increased and the insulin and insulin sensitivity index are decreased in the model group when compared with normal control in streptozotocin induced diabetic rats. The levels of blood urea nitrogen and creatinine are increased with histopathological changes related to diabetic nephropathy in the kidney, which are the glomerular endothelium and mesangial cell proliferation, capillary narrowed, the base-membrane incrassation, glomerular swelling, cysts narrowed and tubules edema. Triterpenoids can decrease the level of blood glucose, blood urea nitrogen and creatinine levels in diabetic rat effectively, increase the insulin sensitivity index and protect renal lesions in diabetic rats. ${ }^{100}$

\section{CONCLUSION}

Various researches on the medicinal use of plant extract is must in the modern era as many chemically synthesized drugs are highly effective in causing many adverse effects in the humans. The phytochemical and pharmacological investigations carried out on $P$. guajava validate the immense potential of this plant in the treatment of numerous diseases. Additional researches are needed for the compound isolation and identification for the product development from P. guajava for the future generations. Every medicinal property of many medicinal plants are also to be determined.

\section{ABBREVIATION USED}

ABTS: 2,2'-azino-bis-3-ethyl benzthiazoline-6-sulphonic acid; ALP: Alkaline Phosphatase; ALT: Alanine Transaminase; AST: Aspartate
Transaminase; CAT: Catalase; DPPH: 1,1-Diphenyl-2-picryl-hydrazyl; FRAP: Ferric Reducing Antioxidant Potential; GPx: Glutathione Peroxidase; GR: Reduced Glutathione; HIV: Human Immunodeficiency Virus; IL: Interleukin (IL-4, IL-6 and IL-8); LPO: Lipid Peroxidation; MMP2: Matrix Metalloproteinases-2; MMP-9: Matrix Metalloproteinases-9; ROS: Reactive Oxygen Species; SOD: Superoxide Dismutase; TNF- $\alpha$ : Tumor Necrosis Factor-Alpha.

\section{CONFLICTS OF INTEREST}

No funding source and there is no conflict of interest.

\section{REFERENCES}

1. Killion KH. The Review of Natural Products, $3^{\text {ed }}$. Facts and Comparison, USA, 2000:250-1.

2. Gutierrez RM, Mitchell S, Solis RV. Psidium guajava: A review of its traditional uses, phytochemistry and pharmacology. J Ethnopharmacol. 2008;117(1):1-27.

3. Hamada S, Kitanaka S. Method of treatment of atopic dermatitis with dried guava leaves. United States Patent. 1999;5:942, 231.

4. Okuda T, Yoshida T, Hatano T, Yakazi K, Ashida M. Ellagitannins of the casuarinaceae, stachyuraceae and myrtaceae. Phytochemistry. 1982;21(12):2871-4.

5. Khadem EHE, MohammedYS. Constituents of the Leaves of Psidium guajava, $L$. Journal of ChemicalSociety. 1959;11:3320-3.

6. Vargas AD, Soto HM, Gonzalez HVA, Engleman EM, Martinez GA. Kinetics of accumulation and distribution of flavonoids in guava (Psiduim guajava). Agrociencia. 2006;40:109-15.

7. Matsuo T, Hanamure N, Shimoi K, Nakamura Y, Tomita I. Identification of (+)gallocatechin as a bio-antimutagenic compound in Psidium guava leaves. Phytochemistry. 1994; 36(4):1027-9

8. Li J, Chen F, Luo J. GC MS analysis of essential oil from the leaves of $P$. guajava. Zhong yao Cai. 1999;22(2):78-80

9. Mercadante AZ, Steck A, Pfander H. Carotenoids from guava (Psidium guajava L.): isolation and structure elucidation. J Agric Food Chem. 1999;47(1):145-51.

10. Begum S, Hassan SI, Siddiqui BS, Shaheen F, Ghayur MN, Gilani AH. Triterpenoids from the leaves of Psidium guajava. Phytochemistry. 2002;61(4):399-403.

11. Begum S, Siddiui BS, Hassan SI. Triterpenoids from Psidium guajava leaves. Nat Prod Lett. 2002;16(3):173-7.

12. Begum S, Hassan, SI, Siddiqui BS. Two new triterpenoids from the fresh leaves of Psidium guajava. Planta Medical. 2002; 68(12):1149-52.

13. Begum S, Ali SN, Hassan SI, Siddiqui BS. Chemical constituents from the leaves of Psidium guajava. Nat Prod Res. 2004;18(2):135-40.

14. Begum S, Ali SN, Hassan SI, Siddiqui BS. A new ethylene glycol triterpenoid from the leaves of Psidium guajava. Nat Prod Res. 2007;21(8):742-8.

15. Yang $X L$, Hsieh KL, Liu JK. Guajadial: an unusual meroterpenoid from guava leaves Psidium guajava. Org Lett. 2007;9(24):5135-8.

16. Ghosh P, Mandal A, Chakraborty P, Rasul MG, Chakraborty M, Saha A. Triterpenoids from Psidium guajava with Biocidal Activity. Indian J Pharm Sci. 2010;72(4):504-7.

17. Shu JC, Chou GX, Wang ZT. One new galloyl glycoside from fresh leaves of Psidium guajava L. Yao Xue Xue Bao. 2010;45(3):334-7.

18. Metwally AM, Omar AA, Harraz FM, El Sohafy SM. Phytochemical investigation and antimicrobial activity of Psidium guajava L. leaves. Pharmacogn Mag. 2010;6(23):212-8.

19. Gao Y, Wang GQ, Wei K, Hai P, Wang F, Liu JK. Isolation and biomimetic synthesis of $( \pm)$-guajadial B, a novel meroterpenoid from Psidium guajava. Org Lett. 2012;14(23):5936-9.

20. Ryu NH, Park KR, Kim SM, Yun HM, Nam D, Lee SG, et al. A hexane fraction of guava Leaves (Psidium guajava L.) induces anticancer activity by suppressing AKT/mammalian target of rapamycin/ribosomal p70 S6 kinase in human prostate cancer cells. J Med Food. 2012;15(3):231-41.

21. Shao $M$, Wang $Y$, Jian $Y Q$, Sun $X G$, Huang $X J$, Zhang $X Q$, et al. Chemical constituents of leaves of Psidium guajava. Zhongguo Zhong Yao Za Zhi. 2014;39(6):1024-9.

22. Jaiarj $P$, Khoohaswan P, Wongkrajang Y, Peungvicha P, Suriyawong P, Saraya ML, et al. Anticough and antimicrobial activities of Psidium guajava Linn. leaf extract. J Ethnopharmacol. 1999;67(2):203-12.

23. Vieira RHS, dos F, Rodrigues D, dos P, Goncalves FA, Menezes FGR, et al. Microbicidal effect of medicinal plant extracts (Psidium guajava Linn. and Carica papaya Linn.) upon bacteria isolated from fish muscle and known to induce diarrhea in children. Instituto de Ciencias do Mar-UFC, Ceara, Brazil. Revista do Instituto de Medicina Tropical de Sao Paulo. 2001;43(3): 145-8.

24. Abdelrahim SI, Almagboul AZ, Omer ME, Elegami A. Antimicrobial activity of Psidium guajava L. Fitoterapia. 2002;73(7):713-5.

25. Limsong J, Benjavongkulchai E, Kuvatanasuchati J. Inhibitory effects of some herbal extracts on adherence of Streptococcus mutans. J Ethnopharmacol. 


\section{4;92(2):281-9}

26. Belemtougri RG, Constantin B, Cognard C, Raymond G, Sawadogo L. Effects of two medicinal plants Psidium guajava L. (Myrtaceae) and Diospyros mespiliformis L. (Ebenaceae) leaf extracts on rat skeletal muscle cells in primary culture. J Zhejiang Univ Sci B. 2006;7(1):56-63.

27. Rattanachaikunsopon P, Phumkhachorn P. Bacteriostatic effect of flavonoids isolated from leaves of Psidium guajava on fish pathogens. Fitoterapia. 2007;78(6);434-6.

28. Mahfuzul Hoque MD, Bari ML, Inatsu Y, Juneja VK, Kawamoto S. Antibacterial activity of guava (Psidium guajava L.) and Neem (Azadirachta indica A. Juss.) extracts against foodborne pathogens and spoilage bacteria. Foodborne Pathog Dis. 2007;4(4):481-8.

29. Athikomkulchai $S$, Watthanachaiyingcharoen $R$, Tunvichuen $S$, Vagamhasuwan $P$ Karnsomkiet $P$, Sae Jong $P$, et al. The development of anti-acne products from Eucalyptus globules and Psidium guajava oil. J Health Res. 2008;22(3):109-13.

30. Anas K, Jayasree PR, Vijayakumar T, Manish KPR. In vitro antibacterial activity of Psidium guajava Linn. leaf extract on clinical isolates of multidrug resistant Staphylococcus aureus. Indian J Exp Biol. 2008;46(1):41-6.

31. Gonçalves FA, Andrade Neto M, Bezerra JN, Macrae A, Sousa OV, FontelesFilho AA, et al. Antibacterial activity of GUAVA, Psidium guajava Linnaeus, leaf extracts on diarrhea-causing enteric bacteria isolated from Seabob shrimp, Xiphopenaeus kroyeri (Heller). Rev Inst Med Trop Sao Paulo. 2008;50(1):11-5.

32. Pelegrini PB, Murad AM, Silva LP, Dos Santos RC, Costa FT, Tagliari PD, et al. Identification of a novel storage glycine-rich peptide from guava (Psidium guajava) seeds with activity against Gram-negative bacteria. Peptides. 2008; 29(8):1271-9.

33. Tavares LS, Rettore JV, Freitas RM, Porto WF, Duque AP, Singulani Jde L, et al. Antimicrobial activity of recombinant Pg-AMP1, a glycine-rich peptide from guava seeds. Peptides. 2014;37(2):294-300.

34. Rahim N, Gomes DJ, Watanabe H, Rahman SR, Chomvarin C, Endtz HP, et al. Antibacterial activity of Psidium guajava leaf and bark against multidrugresistant Vibrio cholerae: implication for cholera control. Jpn J Infect Dis 2010;63(4):271-4.

35. Birdi T, Daswani P, Brijesh S, Tetali P, Natu A, Antia N. Newer insights into the mechanism of action of Psidium guajava L. leaves in infectious diarrhoea. BMC Complement Altern Med. 2010;10(1):33

36. Mao QC, Zhou YC, Li RM, Hu YP, Liu SW, Li XJ. Inhibition of HIV-1 mediated cell-cell fusion by saponin fraction from Psidium guajava leaf. Zhong Yao Cai. 2010;33(11):1751-4

37. Dhiman A, Nanda A, Ahmad S, Narasimhan B. In vitro antimicrobial activity of methanolic leaf extract of Psidium guajava L. J Pharm Bioallied Sci. 2011; 3(2):226-9.

38. Sriwilaijaroen N, Fukumoto S, Kumagai K, Hiramatsu H, Odagiri T, Tashiro M, et al. Antiviral effects of Psidium guajava Linn. (guava) tea on the growth of clinical isolated $\mathrm{H} 1 \mathrm{~N} 1$ viruses: its role in viral hemagglutination and neuraminidase inhibition. Antiviral Res. 2012;94(2):139-46.

39. Masadeh MM, Alkofahi AS, Alzoubi KH, Tumah HN, Bani-Hani K. AntiHelicobactor pylori activity of some Jordanian medicinal plants. Pharm Biol. 2014;52(5):566-9

40. Bisis B, Rogers K, McLaughlin F, Daniels D, Yadav A. Antimicrobial Activities of Leaf Extracts of Guava (Psidium guajava L.) on Two Gram-Negative and GramPositive Bacteria. Int J Microbiol. 2013:7461-65.

41. de Araújo AA, Soares LA, Assunção FMR, de Souza Neto MA, da Silva GR, de Araújo RF Jr, et al. Quantification of polyphenols and evaluation of antimicrobial, analgesic and anti-inflammatory activities of aqueous and acetone-water extracts of Libidibia ferrea, Parapiptadenia rigida and Psidium guajava. J Ethnopharmacol. 2014;156:88-96.

42. Lutterodt GD. Inhibition of gastrointestinal release of acetylcholine by quercetin as a possible mode of action of Psidium guajava leaf extracts in the treatment of acute diarrhoeal disease. J Ethnopharmacol. 1989;25(3):235-47.

43. Morales MA, Tortoriello J, Meckes M, Paz D, Lozoya X. Calcium-antagonist effect of quercetin and its relation with the spasmolytic properties of Psidium guajava L. Arch Med Res. 1994;25(1):17-21.

44. Lozoya X, Meckes M, Abou-Zaid M, Tortoriello J, Nozzolillo C, Arnason JT. Quercetin glycosides in Psidium guajava L. leaves and determination of a spasmolytic principle. Arch Med Res. 1994;25(1):11-5.

45. Han EH, Hwang YP, Choi JH, Yang JH, Seo JK, Chung YC, et al. Psidium guajava extract inhibits thymus and activation-regulated chemokine (TARC/ CCL17) production in human keratinocytes by inducing heme oxygenase-1 and blocking NF-KB and STAT1 activation. Environ Toxicol Pharmacol. 2011;32(2):136-45.

46. Jang M, Jeong SW, Cho SK, Ahn KS, Lee JH, Yang DC, et al. Anti-inflammatory effects of an ethanolic extract of guava (Psidium guajava L.) leaves in vitro and in vivo. J Med Food. 2014;17(6):678-85.

47. Han EH, Hwang YP, Kim HG, Park JH, Choi JH, Im JH, et al. Ethyl acetate extract of Psidium guajava inhibits IgE-mediated allergic responses by blocking FceRI signaling. Food Chem Toxicol. 2011;49(1):100-8.

48. Matsuzaki K, Ishii R, Kobiyama K, Kitanaka S. New benzophenone and quercetin galloyl glycosides from Psidium guajava L. J Nat Med. 2010;64(3):252-6.
49. Qian H, Nihorimbere V. Antioxidant power of phytochemicals from Psidium guajava leaf. J Zhejiang Univ Sci. 2004;5(6):676-83.

50. Akinola OB, Oladosu OS, Dosumu OO. Ethanol extract of the leaves of Psidium guajava Linn enhances sperm output in healthy Wistar rats. Afr J Med Med Sci. 2007;36(2):137-40

51. Wang B, Jiao S, Liu H, Hong J. Study on antioxidative activities of Psidium guajava Linn leaves extracts. Wei Sheng Yan Jiu. 2007;36(3):298-300.

52. Akinola OB, Oladosu OS, Dosumu OO. Spermatoprotective activity of the leaf extract of Psidium guajava Linn. Niger Postgrad Med J. 2007;14(4):273-6.

53. Shabana S, Kawai A, Kai K, Akiyama K, Hayashi H. Inhibitory activity against urease of quercetin glycosides isolated from Allium cepa and Psidium guajava. Biosci Biotechnol Biochem. 2010;74(4):878-80

54. Kim SH, Cho SK, Hyun SH, Park HE, Kim YS, Choi HK. Metabolic profiling and predicting the free radical scavenging activity of guava (Psidium guajava L.) leaves according to harvest time by $1 \mathrm{H}$-nuclear magnetic resonance spectroscopy. Biosci Biotechnol Biochem. 2011;75(6):1090-7.

55. Akinmoladun AC, Obuotor EM, Farombi EO. Evaluation of antioxidant and free radical scavenging capacities of some Nigerian indigenous medicinal plants. J Med Food. 2010;13(2):444-51.

56. Nantitanon W, Okonogi S. Comparison of antioxidant activity of compounds isolated from guava leaves and a stability study of the most active compound. Drug Discov Ther. 2012;6(1):38-43.

57. Fernandes MR, Azzolini AE, Martinez ML, Souza CR, Lucisano-Valim YM, Oliveira WP. Assessment of antioxidant activity of spray dried extracts of $P$ sidium guajava leaves by DPPH and chemiluminescence inhibition in human neutrophils. Biomed Res Int. 2014:382891.

58. Seo J, Lee S, Elam ML, Johnson SA, Kang J, Arjmandi BH. Study to find the best extraction solvent for use with guava leaves (Psidium guajava L.) for high antioxidantefficacy. Food Sci Nutr. 2014;2(2):174-80.

59. Santhoshkumar T, Rahuman AA, Jayaseelan C, Rajakumar G, Marimuthu S, Kirthi AV, Velayutham K, Thomas J, Venkatesan J, Kim SK. Green synthesis of titanium dioxide nanoparticles using Psidium guajava extract and its antibacterial andantioxidant properties. Asian Pac J Trop Med. 2014;7(12):968-76.

60. Feng $X \mathrm{H}$, Wang ZH, Meng DL, Li X.Cytotoxic and antioxidant constituents from the leaves of Psidium guajava. Bioorg Med Chem Lett. 2015; 25(10):2193-8.

61. El Anany AM. Nutritional composition, antinutritional factors, bioactive compounds and antioxidant activity of guava seeds (Psidium Myrtaceae) as affected by roasting processes. J Food Sci Technol. 2015;52(4):2175-83.

62. Vijayakumar K, Vijaya Anand A, Manikandan R. In vitro antioxidant activity of ethanolic extract of Psidium guajava leaves. International Journal of Research Studies in Biosciences. 2015:3(5):145-9.

63. Manikandan R, Vijaya Anand A. Evaluation of antioxidant activity of Pisidum guajava Linn. In streptozotocin-induced diabetic rats. Free Rad Antiox. 2016;6(1):72-6

64. Cheng JT, Yang RS. Hypoglycemic effect of guava juice in mice and human subjects. Am J Chin Med. 1983;11(1-4):74-6.

65. Mukhtar HM, Ansari SH, Ali M, Naved T, Bhat ZA. Effect of water extract of Psidium guajava leaves on alloxan-induced diabetic rats. Pharmazie. 2004;59(9):734-5.

66. Oh WK, Lee CH, Lee MS, Bae EY, Sohn CB, Oh H, et al. Antidiabetic effects of extracts from Psidium guajava. J Ethnopharmacol. 2005;96(3):411-5.

67. Mukhtar HM, Ansari SH, Bhat ZA, Naved T Singh P. Antidiabetic activity of an ethanol extract obtained from the stem bark of Psidium guajava (Myrtaceae). Pharmazie. 2006;61(8):725-7.

68. Wang B, Liu HC, Hong JR, Li HG, Huang CY. Effect of Psidium guajava leaf extract on alpha-glucosidase activity in small intestine of diabetic mouse. Sichuan Da Xue Xue Bao Yi Xue Ban. 2007;38(2):298-301.

69. Owen PL, Martineau LC, Caves D, Haddad PS, MatainahoT, Johns T. Consumption of guava (Psidium guajava $\mathrm{L}$ ) and noni (Morinda citrifolia $\mathrm{L}$ ) may protect betel quid-chewing Papua New Guineans against diabetes. Asia Pac J Clin Nutr. 2008;17(4):635-43

70. Shen SC, Cheng FC, Wu NJ. Effect of guava (Psidium guajava Linn.) leaf soluble solids on glucose metabolism in type 2 diabetic rats. Phytother Res. 2008;22(11):1458-64.

71. Rai PK, Jaiswal D, Mehta S, Watal G. Anti-hyperglycaemic potential of Psidium guajava raw fruit peel. Indian J Med Res. 2009;129(5):561-5.

72. Cheng FC, Shen SC, Wu JS. Effect of guava (Psidium guajava L.) leaf extract on glucose uptake in rat hepatocytes. J Food Sci. 2009;74(5):H132-8.

73. Soman S, Rauf AA, Indira M, Rajamanickam C. Antioxidant and antiglycative potential of ethyl acetate fraction of Psidium quajava leaf extract in streptozotocin-induced diabetic rats. Plant Foods Hum Nutr. 2010;65(4):386-91.

74. Huang CS, Yin MC, Chiu LC. Antihyperglycemic and antioxidative potential of Psidium guajava fruit in streptozotocin-induced diabetic rats. Food Chem Toxicol. 2011;49(9):2189-95

75. Eidenberger T, Selg M, Krennhuber K. Inhibition of dipeptidyl peptidase activity by flavonol glycosides of guava (Psidium guajava L.): a key to the beneficial effects of guava in type II diabetes mellitus. Fitoterapia. 2013;89:74-9.

76. Khan HB, Shanmugavalli R, Rajendran D, Bai MR, Sorimuthu S. Protective 
effect of Psidium guajava leaf extract on altered carbohydrate metabolism in streptozotocin-induced diabetic rats. J Diet Suppl. 2013;10(4):335-44.

77. Guo X, Yoshitomi H, Gao M, Qin L, Duan Y, Sun W, et al. Guava leaf extracts promote glucose metabolism in SHRSP.Z-Leprfa/lzm rats by improving insulin resistance in skeletal muscle. BMC Complement Altern Med. 2013;13(1):52.

78. Okpashi VE, Bayim BP, Obi-Abang M. Comparative Effects of Some Medicina Plants: Anacardium occidentale, Eucalyptus globulus, Psidium guajava, and Xylopia aethiopica Extracts in Alloxan-Induced Diabetic Male Wistar Albino Rats. Biochem Res Int. 2014;203051.

79. Mathur R, Dutta S, Velpandian T, Mathur SR. Psidium guajava Linn. leaf extract affects hepatic glucose transporter-2 to attenuate early onset of insulin resistance consequent to high fructose intake: An experimental study. Pharmacognosy Res. 2015;7(2):166-75.

80. Roy CK, Kamath JV, Asad M. Hepatoprotective activity of Psidium guajava Linn. leaf extract. Indian J Exp Biol. 2006;44(4):305-11.

81. Roy CK, Das AK. Comparative evaluation of different extracts of leaves of Psidium guajava Linn. for hepatoprotective activity. Pak J Pharm Sci. 2010;23(1): 15-20.

82. Rai PK, Mehta S, Watal G. Hypolipidaemic and hepatoprotective effects of Psidium guajava raw fruit peel in experimental diabetes. Indian J Med Res. 2010;131(820):820-4.

83. Conde GEA, Nascimento VT, Santiago SAB. Inotropic effects of extracts of Psidium guajava L. (guava) leaves on the guinea pig atrium. Brazilian Journal of Medical and Biological Research. 2003;36(5):661-8.

84. Ojewole JA. Hypoglycemic and hypotensive effects of Psidium guajava Linn. (Myrtaceae) leaf aqueous extract. Methods and Findings in Experimental and Clinical Pharmacology. 2005;27(10):689-95.

85. Belemtougri RG, Constantin B, Cognard C, Raymond G, Sawadogo L. Effects of two medicinal plants Psidium guajava L. (Myrtaceae) and Diospyros mespiliformis L. (Ebenaceae) leaf extracts on rat skeletal muscle cells in primary culture. J Zhejiang Univ Sci B. 2006;7(1):56-63.

86. Olatunji BI, Odusanya AJ, Raji I, Ladipo CO. Contractile effect of the aqueous extract of Psidium guajava leaves on aortic rings in rat. Fitoterapia. 2007; 78(3):241-3

87. Yamashiro S, Noguchi K, Matsuzaki T, Miyagi K, Nakasone J, Sakanashi M, et al. Cardioprotective effects of extracts from Psidium guajava $\mathrm{L}$ and Limonium wrightii, Okinawan medicinal plants, against ischemia-reperfusion injury in perfused rat hearts. Pharmacology. 2003;67(3):128-35

88. Soman S, Rajamanickam C, Rauf AA, Indira M. Beneficial effects of Psidium guajava leaf extract on diabetic myocardium. Exp Toxicol Pathol. 2013;65 $(1-2): 91-5$.

89. Seo N, ItoT, Wang N, Yao X, Tokura Y, Furukawa F, et al. Anti-allergic Psidium guajava extracts exert an antitumor effect by inhibition of $T$ regulatory cells and resultant augmentation of Th1 cells. Anticancer Res. 2005;25(6A):3763-70.

90. Manosroi J, Dhumtanom P, Manosroi A. Anti-proliferative activity of essential oil extracted from Thai medicinal plants on KB and P388 cell lines. Cancer Lett. 2006:235(1):114-20.

91. Chen KC, Hsieh CL, Peng CC, Hsieh-Li HM, Chiang HS, Huang KD, et al. Brain derived metastatic prostate cancer DU-145 cells are effectively inhibited in vitro by guava (Psidium guajava L.) leaf extracts. Nutr Cancer. 2007;58(1):93-106.

92. Chen KC, Hsieh CL, Huang KD, Ker YB, Chyau CC, Peng RY. Anticancer activity of rhamnoallosan against DU-145 cells is kinetically complementary to coexisting Polyphenolics in Psidium guajava budding leaves. J Agric Food Chem. 2009;57(14):6114-22.

93. Chen KC, Peng CC, Chiu WT, Cheng YT, Huang GT, Hsieh CL, et al. Action mechanism and signal pathways of Psidium guajava $\mathrm{L}$. aqueous extract in killing prostate cancer LNCaP cells. Nutr Cancer. 2010;62(2):260-70.

94. Park KR, Nam D, Yun HM, Lee SG, Jang HJ, Sethi G, et al. $\beta$-Caryophyllene oxide inhibits growth and induces apoptosis through the suppression of $\mathrm{PI} 3 \mathrm{~K} / \mathrm{AKT} / \mathrm{mTOR} / \mathrm{S} 6 \mathrm{~K} 1$ pathways and ROS-mediated MAPKs activation. Cancer Lett. 2011;312(2):178-88.

95. Peng $\mathrm{CC}$, Peng $\mathrm{CH}$, Chen $\mathrm{KC}$, Hsieh $\mathrm{CL}$, Peng RY. The Aqueous Soluble Polyphenolic Fraction of Psidium guajava Leaves Exhibits Potent Anti-Angiogenesis and Anti-Migration Actions on DU145 Cells. Evid Based Complement Alternat Med. 2011:219069.

96. Bontempo P, Doto A, Miceli M, Mita L, Benedetti R, Nebbioso A, et al. Psidium guajava L. anti-neoplastic effects: induction of apoptosis and cell differentiation Cell Prolif. 2012;45(1):22-31.

97. Rizzo LY, Longato GB, Ruiz AL, Tinti SV, Possenti A, Vendramini-Costa DB, et al. In vitro, in vivo and in silico analysis of the anticancer and estrogen-like activity of guava leaf extracts. Curr Med Chem. 2014;21(20):2322-30.

98. Kim C, Cho SK, Kapoor S, Kumar A, Vali S, AbbasiT, et al. $\beta$-Caryophyllene oxide inhibits constitutive and inducible STAT3 signaling pathway through induction of the SHP-1 protein tyrosine phosphatase. Mol Carcinog. 2014;53(10):793-806.

99. Lin CY, Yin MC. Renal protective effects of extracts from guava fruit (Psidium guajava L.) in diabetic mice. Plant Foods Hum Nutr. 2012;67(3):303-8.

100. Kuang OT, Zhao JJ, Ye CL, Wang JR, Ye KH, Zhang XQ, et al. Nephro-protective effects of total triterpenoids from Psidium guajava leaves on type 2 diabetic rats. Zhong Yao Cai. 2012;35(1):94-7.

\section{PICTORIAL ABSTRACT}

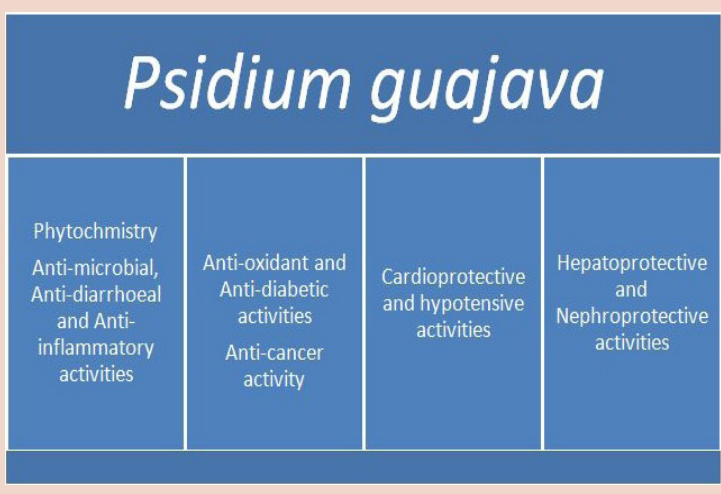

\section{SUMMARY}

- The traditional medicinal system use plants to cure various diseases.

- This review confirmed the ability of Psidium guajava and its numerous pharmacological activities found its rightful place in traditional medicine.

\section{ABOUT AUTHOR}

Dr. A. Vijaya Anand: Associate Professor and Head, Department of Human Genetics and Molecular Biology, Bharathiar University, Coimbatore, Tamil Nadu, India. He has published multiple scientific articles in international journals. He is currently engaged in the field of phytopharmacology, neurogenetics, medical genetics and clinical biochemistry. 